period. The policy of the University Grants Committee to make no recurrent grants until a university receives its first students has postponed the appointment of key academic staff and necessitated the taking of decisions affecting the shape of a university for years to $\operatorname{come}$, without the benefit of continuous academic advice. The very short period in advance for which capital grants have been indicated has also delayed physical planning, and while it is essential that a new university should be assured of the sums of money that may be committed over each of the next five years, it would be still more helpful to indicate capital grants for ten years ahead. This financial assurance would also assist the start of the scholarly and scientific work of the university.

\title{
REPRODUCTION OF THE AFRICAN ELEPHANT
}

\begin{abstract}
CONTINUING his researches on the reproduction of $\checkmark$ the African elephant, Dr. J. S. Perry has examined eight foetal specimens collected during a two-year stay in Uganda*. In one paper Prof. E. C. Amoroso and Dr. Perry have investigated the foetus in utero in a series ranging from the smallest, weighing only $2 \mathrm{~g}$, to a nearterm male of $120 \mathrm{~kg}$. Adequate preservation in the field enabled the authors to describe not only the gross structure of the foetal membranes, but also the microscope anatomy of the placenta. Tho placenta of the elephant is zonary, but the allanto-chorionic villi are thinned or interrupted at intervals on the circumference of the chorionic sac. The large allantois is quadrilocular; its four sacs completely separate amnion and chorion, fusing with the former and meeting over the back of the foetus. A yolk sac was present in the youngest foetus of approximately two months gestation. The endodermal lining of the allantois bears a large number of mushroom-shaped "allantoic pustules" of unknown function.

The placenta is of the vaso-chorial type of Amoroso and Wislocki. The single-layered trophoblast is partly cellular and partly syncytial. Marginally maternal blood

* The Foetal Membranes and Placenta of the African Elephant (Loxodonta africana). By E. C. Amoroso and J. S. Perry. The Structure and Develop Perry, Phil. Trans. Roy. Soc., B, 248, 1, 35 (1964).
\end{abstract}

\section{CHEMISTRY AND PHYSIOLOGY OF 'DORMINS' IN SYCAMORE}

\section{Identity of Sycamore 'Dormin' with Abscisin II}

CROWTH-inhibitory compounds ('dormins') play a $J$ part in the regulation of bud-growth of some woody perennials ${ }^{1-5}$. In sycamore and in birch, a change from long-day to short-day conditions produces a marked increase in dormin concentration and the buds stop growing; dormin-containing extracts of leaves from birch plants grown under short-day conditions inhibit the growth and induce the formation of resting buds in actively growing birch seedlings maintained under long-day conditions. Owing to the considerable technical difficulties attending the determination of bud-inducing activity, concentration of dormin is usually estimated by inhibition of wheat coleoptile growth.

On the other hand, Addicott et $a l .^{6,7}$ have isolated a plant hormone (abscisin II) from young cotton fruit by following its abscission-accelerating effect in cotton explants. Abscisin II was also found to inhibit oat coleoptile growth ${ }^{6,7}$. We have isolated the dormin from sycamore (Acer pseudoplatanus, L.) in crystalline form and have established its identity with abscisin II.

Chopped, dried sycamore leaves, collected in the autumn of 1963 , were extracted at $4^{\circ}$ with $4: 1(\mathrm{v} / \mathrm{v})$ methanol : water. The methanol was removed under reducod pressure; the residual aqueous solution, decanted from the precipitated chlorophyll and acidified to $p H$ 3.5 , was extracted with ether. The dormin was extracted from the ethereal solution into aqueous sodium bicarbonate; continuous ether-extraction of the bicarbonate solution, adjusted to $p \mathrm{H} 8 \cdot 0$, removed most of the weakly exudes and is ingested by the cytotrophoblast. Centrally on the placental band active phagocytosis occurs. The elephant, hyrax and manatee "share a number of features in the arrangement of the foetal membranes and in the detailed structure of the placenta". Fourteen half-tone plates illustrate the work.

In the second paper, which is an extension of that published in 1953, Dr. Perry describes the reproductive organs of the female African elephant in foetal and young animals. The remarkable feature of the external genitalia is the similarity between male and female, in that the urogenital canal has been carried forward on the belly of the female to a point close behind the umbilicus, to a position similar to that of the male opening. The uterine horns undergo a ram's horn flexure, as in some ungulates, before uniting to form the body of the uterus, but the lumina remain separate for most of its length, and it is here that a one-sided conception occurs. The muscles of the external portion of the female genitalia are described. There are four plates of photographs of dissections and transverse sections of the reproductive tract, and seventeen text figures.

These papers give us for the first time a clear picture of the foetal membranes and placenta of the African elephant. acidic inactive compounds; subsequent acidification to $p H \mathbf{H} \cdot 5$, ether-extraction, and evaporation of the ethereal solution yielded a rancid-smelling gum containing the dormin. This was dissolved in a slight excess of aqueous sodium hydroxide and treated with aqueous lead acetate which precipitated much inactive material, but left dormin in solution, from which it was extracted with ether after acidification. Further purification was by column chromatography (silicic acid, eluted with benzeno-other mixtures) followed by thin-layer chromatography ('Kieselgel-(G'), developed with a propanol-butanol-ammoniawater $(6: 2: 1: 2 \mathrm{v} / \mathrm{v})$ mixture. This gave a colourless partly crystalline gum, recrystallization of which from benzene yielded $260 \mu \mathrm{g}$ of the dormin as minute platelets, m.p. $\sim 160^{\circ}$ (Kofler block), which sublimed at $\sim 130^{\circ}$ in a high vacuum. For abscisin II, Addicott et al.$^{6,7}$ give m.p. $160^{\circ}-161^{\circ}$, subl. $120^{\circ}$.

Inhibitory activity was followed by germinating excised wheat embryos ${ }^{8}$ for $48 \mathrm{~h}$ at $27^{\circ}$ in the dark in $0.01 \mathrm{M}$ sodium phosphate buffer ( $p \mathrm{H} 7.4$ ) containing the test material at five or more geometric dilutions. Probit percentage reductions in coleoptile length were plotted against $\log _{10}$ concentration to give a straight line. The concentration reducing length by 50 per cent was used to compare the activities of the test material. We have detected only one compound showing high growth-inhibitory activity in sycamore leaves.

The molecular weight of the dormin, determined by mass-spectrometry, was 264 , identical with that reported ${ }^{6,7}$ for abscisin II. The infra-red spectrum (potassium 